For personal use only. Not to be reproduced without permission of the publisher (editorial@gabi-journal.net).

\section{Austria increases dialogue in order to involve physicians more with biosimilars}

\section{Christoph Baumgärtel, MD}

Comment on the GaBI Journal article titled The potential for doctors to contribute to biosimilar guidelines [1] and the GaBI Online article titled Dialogue needed to build confidence in biosimilars [2], both by GaBI Journal Editor, Dr Julie Clayton.

I n September 2012, Austrian doctors were given reassurance that pharmacists would not make the decision to automatically switch patients from brand-name drugs to biosimilars without the involvement of doctors, and that stringent regulations were in place regarding the safety and efficacy of biosimilars.

In September 2012, the Austrian Society for Pharmaceutical Medicine together with representatives of the Austrian Regulatory Authority and the Austrian Main Association of Social Health Insurance gave hospital and resident doctors an information update about the meaning and potential use of biosimilars, particularly for the benefit of those who are hesitant about prescribing biosimilars. The meeting took place at the largest hospital and medical school in Austria, the General Hospital Vienna, and provided information about the registration and authorisation processes and the mandatory comparability testing against the reference product. Many new biosimilars are likely to be authorised and made available soon, following tests for safety and efficacy via the centralised procedure, leading to upright authorisations in all 27 EU-Member States. As common reluctance to use biosimilars is mainly based on lack of information, this session was an opportunity to answer as many questions as possible.

One major issue was the automatic substitution with biosimilars. Representing the Austrian Regulatory Authority I explained that it is currently not advised that pharmacists automatically substitute a reference product with a biosimilar. Rather, the
European Medicines Agency (EMA) states that the decision to use a biosimilar should always involve a well-informed physician.

In the US, automatic substitution with biosimilars is at least a theoretical possibility, owing to a specific, step-wise approval process which first requires biosimilarity to be shown and then interchangeability. In contrast, EMA does not take responsibility for decisions on interchangeability and/or substitution. Instead, it is for the national competent authorities of EU-Member States to decide based on the scientific evaluation performed by EMA. This could potentially lead to different approaches in the different Member States. However, there seems to be unanimous disapproval of the idea of automatic switching by pharmacists without the involvement of doctors.

I underscored that even by now there is a good opportunity for increasing the uptake of biosimilars in Austria by promoting their use as a starting treatment for new patients rather than by switching existing therapies to biosimilars. Austria already has a very high penetration with biosimilars, ranking third in the EU in 2011, with a defined daily dose of 0.09 per population head. In the case of generics, research by the social insurance system had shown that merely starting new patients on treatment with generics could have a marked effect on raising the penetration rate. Similar effects can be expected for biosimilars.

Hearing that they would remain directly involved in decisions over treatment with a biosimilar seemed to alleviate a major concern for the participating Austrian physicians [1]. However, they will be obliged to

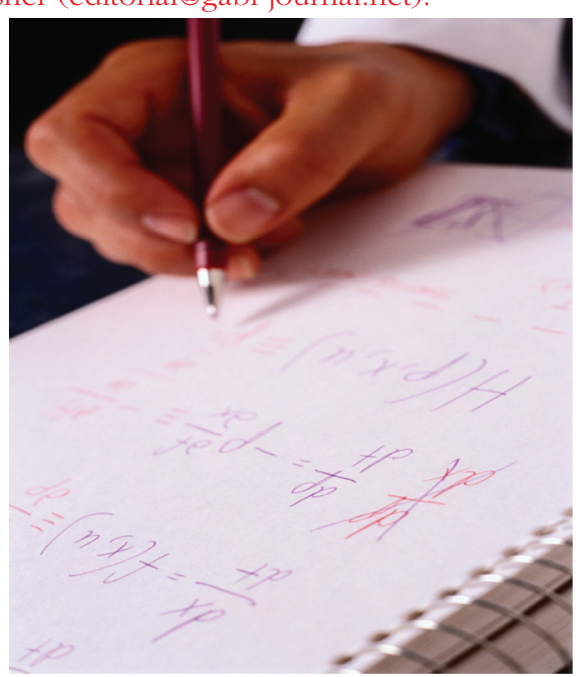

choose biosimilars more often in order to save a huge amount of money for the public health system. Mag Jutta Piessnegger of the Austrian Main Association of Social Health Insurance explained that biosimilars will be priced in Austria in the same way generics are priced, meaning that in a complex system of price reductions, after biosimilar market entry, biosimilars must be priced at 48 to 60 per cent below the cost of the originator, allowing room for substantial savings.

The Austrian Regulatory Authority is interested in continuing to cooperate and seek to have further dialogue with Austrian physicians so that they can make well-informed decisions regarding biosimilar use [2].

\section{Competing interests: None.}

Provenance and peer review: Not commissioned, internally peer reviewed.

\section{References}

1. Clayton J. The potential for doctors to contribute to biosimilar guidelines. Generics and Biosimilars Initiative Journal (GaBI Journal). 2012;1(3-4):152. doi:10.5639/ gabij.2012.0103-4.039

2. GaBI Online - Generics and Biosimilars Initiative. Dialogue needed to build confidence in biosimilars [www.gabionline.net]. Mol, Belgium: Pro Pharma Communications International; [cited 2012 Dec 3]. Available from: www.gabionline.net/Biosimilars/ Research/Dialogue-needed-to-build-confidence-inbiosimilars?

DOI: 10.5639.gabij.2013.0201.003

Copyright @ 2013 Pro Pharma Communications International

Author: Christoph Baumgärtel, MD, Department Head, Department Safety and Efficacy Assessment of Medicinal Products, Institute Marketing Authorisation of Medicinal Products \& LCM, AGES PharmMed-Austrian Medicines and Medical Devices Agency, and Austrian Federal Office for Safety in Health Care, European Expert in Pharmacokinetics Working Party and Safety Working Party of EMA, Member of Austrian Prescription Commission, 5 Traisengasse, AT-1200 Vienna, Austria

Submitted: 18 November 2012; Revised: 3 December 2012; Accepted: 4 December 2012; Published online first: 7 December 2012 